\title{
Reflexões sobre o processo de aprendizagem social do turismo como prática na orla marítima de João Pessoa/PB
}

Reflections on the social learning process of tourism as practice in waterfront of João Pessoa/PB

Reflexiones sobre el proceso de aprendizaje social del turismo como práctica en costa marítima de João Pessoa/PB

http://dx.doi.org/10.18472/cvt.17n3.2017.1137

Erica Dayane Chaves Cavalcante < ericaccx@gmail.com > Universidade Federal da Paraíba (UFPB), João Pessoa, PB, Brasil

Marcelo de Souza Bispo <marcelodesouzabispo@gmail.com > Universidade Federal da Paraíba (UFPB), João Pessoa, PB, Brasil

Lídia da Cunha Soares 〈lidiacsoares@gmail.com > Universidade Federal da Paraíba (UFPB), João Pessoa, PB, Brasil Faculdade Adventista Paranaense, Ivatuba, PR, Brasil

CRONOLOGIA DO PROCESSO EDITORIAL

Recebimento do artigo: 14-out-2015

Aceite: 25 -ago-2017

FORMATO PARA CITAÇÃO DESTE ARTIGO

CAVALCANTE, E. D. C.; BISPO, M. de S.; SOARES, L. da C. Reflexões sobre o Processo de Aprendizagem Social do Turismo como Prática na Orla Marítima de João Pessoa/PB. Caderno Virtual de Turismo. Rio de Janeiro, v. 17, n. 3, p. 34-49, dez. 2017.

REALIZAÇÃO

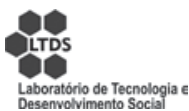

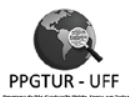

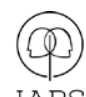

APOIO INSTITUCIONAL

EDIÇÃO

PATROCÍNIO

COPPE

UFR] 


\section{RESUMO}

O objetivo deste estudo consistiu em refletir sobre o processo de aprendizagem social do turismo como prática (TAP) na Orla Marítima de João Pessoa/PB. Foi considerada ainda a compreensão do conjunto de elementos sociomateriais (humanos e não humanos) que alicerçam o TAP na Orla Marítima. Sob a epistemologia das práticas sociais para coleta e análise de material empírico foi utilizada a etnometodologia. Em consonância, como técnicas de coleta, utilizaram-se conversas informais, observação direta e diários de campo. Os resultados indicam que os processos de aprendizagem ocorrem por meio da experiência, socialização, participação e engajamento, sendo intermediados por elementos imateriais (não humanos), tais como a linguagem particularizada e a própria cultura local. Como conclusões, com base nos resultados, podese afirmar que os processos de aprendizagem é o que permite que o TAP possa se realizar e se aprimorar no contexto estudado, visto que atores sociais relataram que empreenderam como resultado da aprendizagem e interação com outros atores e que esse mesmo processo de aprendizagem permite que o empreendimento se aprimore ao longo do tempo, assim um aspecto que influencia na utilização e organização do espaço Orla, possibilitando que o turismo aconteça e aperfeiçoe-se.

Palavras-chave: Processos de Aprendizagem. Turismo como Prática. João Pessoa. Etnometodologia.

\section{ABSTRACT}

The objective of this study is to reflect on the process of social learning and practical tourism (TAP) in Waterfront of João Pessoa/PB. It was also considered understanding of the set of sociomateriais elements (human and non-human) that underpin the TAP in Waterfront. Under the epistemology of social practices, empirical data collection and analysis was used ethnomethodology. As collection techniques, we used informal conversations, direct observation and field diaries. The results indicate that the learning processes occur through experience, socialization, participation and engagement, being mediated by intangibles (nonhuman), such as individualized language and the local culture itself. We conclude that the process of learning influences and is influenced by the TAP, which allows human social actors undertake in Waterfront, making it an organizational space result of organizing.

Keywords: Learning Process. Tourism as Practice. João Pessoa. Ethnomethodology.

\section{RESUMEN}

El objetivo de este trabajo es reflexionar sobre el proceso de aprendizaje social y el turismo como práctica (TAP) en el costa marítima de João Pessa/PB. También se consideró la comprensión del conjunto de sociomateriais elementos (humanos y no humanos) que sustentan el TAP en costa marítima. Bajo la epistemología de las prácticas sociales, se utilizó la recopilación de datos empíricos y análisis etnometodología. Como técnicas de recolección, se utilizó conversaciones informales, observación directo y diarios de campo. Los resultados indican que los procesos de aprendizaje se producen a través de la experiencia, la socialización, la participación y compromiso, siendo mediado por los intangibles (no humanos), como el lenguaje individualizado y la propia cultura local. Llegamos a la conclusión de que el proceso de aprendizaje de influencias y está influenciado por el TAP, que permite a los actores sociales humanos se comprometen en costa marítima, por lo que es un resultado espacio organizacional de los procesos organizacionales.

Palavras clave: Proceso de aprendizaje. Turismo como práctica. João Pessoa. Etnometodología. 


\section{INTRODUÇÃO}

O turismo é considerado uma importante atividade socioeconômica dotada de grande complexidade que produz efeitos onde ocorre, sejam estes ruins para determinada localidade, ou bons, uma vez que envolve infraestrutura, serviços, aspectos ambientais e atrativos de diversas ordens, razões determinantes para o surgimento e a sustentação de um destino turístico (MINISTÉRIO DO TURISMO, 2014). Enquanto ciência, tradicionalmente, a pesquisa em turismo é conservadora, centrando-se no positivismo, ou seja, em estudos que tratam desse fenômeno como algo objetivo que pode ser universalizado, deixando de lado fenômenos subjetivos e os resultados da própria construção social, o que limita a construção de uma plataforma teórica sobre o tema (NECHER, 2011; LAMERS; DUIM; SPAARGAREN, 2017). Contudo, já existe na literatura críticas ao paradigma positivista, abrindo espaço para outras formas de pensar e pesquisar turismo (COHEN; COHEN, 2012; BISPO, 2016a; LAMERS; DUIM; SPAARGAREN, 2017). Necher (2011) explica que a preocupação com os pressupostos epistemológicos no turismo é recente e que antes os estudos estavam mais voltados para estratégias de mercado, aplicação prática e não visavam à criação de conhecimento e desenvolvimento teórico. O autor ainda critica os métodos racionais positivistas para os estudos do turismo explicando que eles não fazem o campo avançar e sugere a adoção de estratégias de investigação interpretativas, críticas e reflexivas e a adoção de estudos inter e transdisciplinares.

Assim como Necher (2011), outros autores já têm adotado estratégias metodológicas mais interpretativas, como os que trabalham com a Teoria Ator-Rede (TAR) em turismo (JÓHANNESSON, 2005; DUIM, 2007; REN, 2011; COHEN; COHEN, 2012), com a fenomenologia (COUSIN; O'GORMAN; MARC STIERAND, 2010) e com estudos baseados em prática (CAVALCANTE; BISPO; SOARES, 2015; BISPO, 2016a; BISPO, 2016b), que pensa o turismo a partir de uma ontologia baseada nas práticas sociais.

Lamers, Duim e Spaargaren (2017) também advogam a epistemologia das práticas sociais para o turismo, dado que se parte do entendimento das práticas sociais como ponto inicial para a compreensão do tema e sua teorização, não se concentrando apenas em agentes individuais ou estruturas sociais. Para os autores, uma agenda de estudo nessa perspectiva, poderia contemplar três segmentos: análise aprofundada do consumo de turismo ou das suas práticas de produção, análise das mudanças no processo do turismo ao longo do tempo, e a compreensão da incorporação das práticas de turismo.

Com efeito, este estudo visa a contribuir para a geração de conhecimento em turismo se utilizando de uma estratégia de investigação construtivista e uma metodologia qualitativa - a etnometodologia, alinhada à abordagem dos estudos baseados em prática, no intuito de possibilitar a compreensão do turismo como prática (TAP) em um espaço organizacional, sendo este a Orla Marítima de João Pessoa/PB.

João Pessoa, capital da Paraíba, localizada no Nordeste do Brasil, é um dos 65 destinos indutores do turismo brasileiro (MINISTÉRIO DO TURISMO, 2014) e possui 24 quilômetros de orla, o que impulsiona o turismo local (JOÃO PESSOA, 2014). A Orla Marítima de João Pessoa/PB é o resultado de múltiplos processos organizativos que em conjunto não apenas constituem a orla, mas também o turismo que nela acontece. O turismo, nesse contexto, é a soma de várias práticas sociomateriais (uma textura), em que o visitante pode aproveitar das mais variadas atividades, como esportes terrestres e aquáticos, restauração e hospitalidade, desfrutando de um espaço que promove o relaxamento e o prazer (CAVALCANTE; BISPO; SOARES, 2015). Logo, compreende-se neste estudo o turismo como uma prática sociomaterial. 
É importante mencionar que a aprendizagem assume importante papel perante essa prática, mesmo sendo um tema pouco explorado em estudos em turismo. Pela prática, representar um conjunto de ações mantidas e aprimoradas ao longo do tempo, mediadas pela interação social, a aprendizagem na geração de conhecimento é uma condição básica para que o indivíduo se torne parte social de um mundo em constante construção (GHERARDI; NICOLINI; ODELLA, 1998). Dessa forma, o objetivo deste estudo é refletir, por meio de uma etnometodologia, como se dá o processo de aprendizagem social do turismo como prática sociomaterial na Orla Marítima de João Pessoa/PB.

Ademais, este artigo se encontra dividido da seguinte forma, além desta introdução: na segunda seção é levantada uma reflexão sobre as abordagens sociológicas do turismo; na terceira se discorre sobre a aprendizagem social na perspectiva da prática; na quarta seção é detalhado o caminho metodológico percorrido na realização deste estudo; na quinta seção são apresentados os resultados da pesquisa demonstrando como o turismo se realiza como uma prática; e, finalmente, na sexta seção são apresentadas as conclusões e reflexões finais.

\section{ABORDAGENS SOCIOLÓGICAS DO TURISMO - CONVERGINDO PARA O CAMPO DAS PRÁTICAS}

As contribuições da sociologia para a compreensão do turismo e dos fenômenos a ele relacionados são vastas na literatura internacional (e.g.: ENZENSBERGER, 1996; PAGET; DIMANCHE; MOUNET, 2010; EDENSOR, 2001). Temas como a sociologia do lazer (e.g.: HAMMERICH, 2003; MALCOM; MANSFIELD, 2013), cultura e turismo são exemplos da relevância do papel da sociologia nos estudos turísticos. Na esteira das contribuições já mencionadas, neste estudo adotamos como referência sociológica uma epistemologia da prática social (RECKVITZ, 2002; NICOLINI, 2013; BISPO, 2016a; 2016b), já considerada por alguns autores do turismo por meio da Teoria Ator-Rede (TAR), a exemplo de Edensor (2001), Jóhannesson (2005), Cohen e Cohen (2012) e Duim (2007).

Edensor (2001, p. 60) aborda o turismo na perspectiva do paradigma da performatividade, considerando-o um fenômeno social a partir do qual atores podem interagir. De forma complementar, Cohen e Cohen (2012) apresentam o paradigma da performatividade e mais dois paradigmas que nas suas concepções muito têm a contribuir para a noção de turismo em uma visão mais ampla que dê conta de entendê-lo de maneira mais complexa e dinâmica, são eles: a mobilidade e a TAR.

A TAR é considerada por muitos autores (SCHATZKI, 2001; GHERARDI, 2006; BISPO, 2013) como uma das possibilidades dos estudos baseados em prática. Entretanto, Cohen e Cohen (2012), assim como Jóhannesson (2005), não trazem o conceito de prática ao tratar da TAR nos seus trabalhos.

Contudo, é o trabalho de Bispo (2016a) que consolida a noção de Turismo como prática ampliando a compreensão do fenômeno turístico para além do deslocamento de pessoas e mostrando como práticas e praticantes normalmente considerados como não turísticos são fundamentais para a compreensão de uma nova posição ontológica do turismo.

Os estudos baseados em prática formam um grande guarda-chuva que abriga um conjunto de teorias chamadas de "teorias da prática" (SCHATZKI, 2001; GHERARDI, 2006; NICOLINI, 2013), entre as quais as sociomaterialidade que juntamente com a etnometodologia (GARFINKEL, 1967) orientam este 
trabalho. A sociomaterialidade (ORLIKOWSKI; SCOTT, 2013) é uma abordagem ainda pouco utilizada nos estudos turísticos, mesmo oferecendo potencial para compreensão do turismo enquanto fenômeno dinâmico e para além da ideia de Home and Away. No turismo, a sociomaterialidade representa pensar na sua produção pautada na relação entre atores-humanos (turistas e não turistas); e os não humanos (objetos e artefatos), incluindo a imaterialidade (as leis, a cultura, a linguagem, a música e a dança), estes que são condicionantes sociais (LEONARDI, 2012; DUIM; REN; JÓHANNESSON, 2012; BISPO, 2016a).

Já a etnometodologia é uma vertente do campo da sociologia que tem como fundamento a busca pela compreensão da organização social pela lógica dos membros que compõem os grupos sociais investigados (GARFINKEL, 1967; COULON, 2005; RAWLS, 2008; BISPO; GODOY, 2012, 2014). Em suma, a etnometodologia tem interesse em compreender porque determinados grupos sociais se organizam e se comportam da maneira que fazem no seu cotidiano.

Os estudos baseados em prática oferecem uma abordagem que permite compreender a ordem social, os fenômenos coletivos e o entendimento de como ocorre a organização social (GHERARDI, 2006) em uma perspectiva pós-humanista, já que consideramos os elementos não humanos na análise social. Partem do princípio de que as atividades são parte corpórea das práticas e mediadas por artefatos e objetos híbridos (SCHATZKI, 2001). É importante esclarecer que dentro da abordagem das práticas, o entendimento vai além da noção de rotina, ação individual, ou simplesmente o fazer determinada atividade. Embora seja possível alcançar algumas definições para o termo, entendemos mais importante avançar na compreensão dos seus pressupostos e significados.

Gherardi (2006) afirma que a noção de prática respeita princípios que podem ajudar a desenhar um melhor entendimento do termo. Destarte, cinco características são apontadas: (a) a prática se refere à forma como os significados são atribuídos a determinado grupo de execução de atividades (situadas) e como o reconhecimento dessas atividades é obtido; (b) a prática se relaciona à fragmentação temporal em que um conjunto de atividades ocorre; (c) a prática é um fenômeno reconhecido socialmente pelos seus praticantes; (d) a prática reflete a forma como o mundo é organizado; (e) a prática é dinâmica e inacabada.

Desse modo, uma prática pode ser considerada "um modo relativamente estável no tempo e socialmente reconhecido de ordenar elementos heterogêneos em um conjunto coeso" (GHERARDI, 2006, p. 34). Ainda sobre o entendimento das práticas, nas palavras de Gherardi (2009, p. 536):

\footnotetext{
Práticas não são apenas padrões recorrentes de ação (nível de produção), mas também padrões recorrentes de ação socialmente sustentada (produção e reprodução). O que as pessoas produzem em suas práticas situadas não é só trabalho, mas também a (re)produção da sociedade. Nesse sentido, a prática é um conceito analítico que permite interpretação de como as pessoas alcançam o ser-no-mundo. A prática não é reconhecida fora do seu significado intersubjetivamente criado e o que torna possível a reprodução competente de uma prática e o seu refinamento ao ser praticado (ou o seu abandono) é a negociação constante do que é pensado para ser uma maneira correta ou incorreta de praticar dentro da comunidade de seus praticantes.
}

Inspirados pela epistemologia das práticas sociais, concordamos com Cohen e Cohen (2012) que o turismo precisa ser entendido como um fenômeno mais complexo do que a simples ideia de home and away, em direção a uma compreensão mais performática (performance como ação), concordamos com Bispo (2016a) na compreensão do "turismo como prática - TAP" defendendo que o turismo pode ser melhor compreendido enquanto processo organizativo de um conjunto (textura) de práticas sociais do que simplesmente a partir do deslocamento de pessoas. Portanto, essas práticas são constituídas por um arranjo de atividades oriundas das interações de humanos e não humanos (GHERARDI, 2006, 2009, 2012; LATOUR, 2005), ou simplesmente sociomateriais. Com efeito, a construção da atividade turística 
como prática passa, necessariamente, pela compreensão de um processo de aprendizagem social e que é apresentado a seguir.

\section{Aprendizagem em uma perspectiva sociológica}

A abordagem social da aprendizagem vem se tornando uma vertente útil na compreensão de como ocorre a aprendizagem no contexto das práticas (WENGER, 1998, 2003; GHERARDI, 2000). Essa abordagem se opõe à teoria cognitiva tradicional (a visão puramente cognitiva), a qual detém maior parte de teorias sobre educação e aprendizagem (FOX, 1997). A abordagem da cognição é considerada por Jarvis (2006) como algo que vai além de um conjunto de teorias sobre como ocorre a aprendizagem, ela envolve um foco considerável em como os indivíduos pensam, sabendo que o conhecimento se encontra armazenado na mente e é transmitido por processos mentais. Percebe-se, por meio de Freire (1970), como é a visão dos cognitivistas em relação ao aprendiz, este como sendo um recipiente ou consumidor de um tipo abstrato de conhecimento avulso e fora de sua cabeça, em que o professor organiza e deposita no aprendiz, respeitando o conceito bancário de educação e ignorando o contexto da aprendizagem, o engajamento e a interação social dos indivíduos que é base na perspectiva social (GHERARDI; NICOLINI; ODELLA, 1998).

É importante mencionar o que é colocado por Marshall (2008). O autor afirma que a aprendizagem social não é incomensurável às abordagens construtivistas e cognitivas, na medida em que assume a existência de processos mentais dos indivíduos, memória, construção de significados, experiências conjuntas, percepção e reflexão (DIDIER; LUCENA, 2008). Marshall (2008) esclarece que a cognição é uma abordagem específica e que os quadros/esquemas cognitivos norteiam os conhecimentos que se tornam base para a construção, reprodução e a potencial transformação das práticas, por meio da relação entre a ação rotineira e a ação reflexiva. Já a abordagem sociológica das práticas é considerada mais holística e inclui mais elementos que apenas a mente. Inclui-se o contexto social, cultural, material e histórico e, ainda, o pensar, o fazer e o ser.

De forma geral, conforme Gherardi, Nicolini e Odella (1998), a perspectiva social da aprendizagem remove o alvo da aprendizagem como manejo do conhecimento e das informações tidos como objetos e a recoloca como processos de interação e participação dos indivíduos em um dado contexto social. $\mathrm{E}$, ainda, nessa perspectiva não se ignora por completo os processos cognitivos, apenas o foco se volta para compreensão de como se dão os engajamentos no contexto social em que o indivíduo se encontra inserido, melhor caracterizando esse engajamento a fim de perceber os processos de aprendizagem que são abrigados pelas ações coletivas dos indivíduos evidenciadas pelas práticas sociais que delas emergem (GHERARDI, 2006).

Conforme Bispo e Mello (2012), o posicionamento epistemológico da perspectiva social de aprendizagem vai além de um acontecimento meramente individual para uma compreensão a partir de que aprendizagem é um fenômeno coletivo e que é acessado quando as pessoas estão engajadas em uma prática. "O ponto fundamental da abordagem sociológica, independentemente do posicionamento epistemológico, está assentado na ideia de que o conhecimento não está nas mentes dos indivíduos, mas é produto de uma estrutura" (BISPO, 2013, p. 137).

De acordo com Gherardi (2000), o aprender e o conhecer são inseparáveis do fazer, e que o conhecimento não se encontra abrigado exclusivamente na mente dos indivíduos e tem seu protagonismo 
no meio social em que o indivíduo age e interage. A aprendizagem, porém, coabita tanto na mente quanto nas práticas sociais. Nessa perspectiva, a relação entre aprendizagem e conhecimento é mediada pela linguagem. Considera-se a linguagem não como apenas um transmissor de conhecimento, mas como um fator central na concepção da ação no mundo social, ou seja, a linguagem se trata de um intermediador do processo social, uma vez que ela permite que a interação entre pessoas seja promovida, possibilitando a geração de conhecimento e, consequentemente, a aprendizagem (GHERARDI; NICOLINI; ODELLA, 1998; GHERARDI, 2006).

Ao se falar sobre a perspectiva de aprendizagem adotada para a condução deste estudo, a ênfase é dada na ação coletiva que gera conhecimentos relevantes para sua existência, conhecimentos estes materiais, imateriais e não necessariamente de uso econômico. Nesse sentido, Gherardi e Nicolini (2001) recomendam que a aprendizagem seja estudada a partir de dois conceitos que interagem com a etnometodologia (método utilizado para este estudo a ser apresentado a seguir), sejam estes a noção de participação em práticas e a reflexividade. Nessa perspectiva, para que a aprendizagem se concretize e o conhecimento seja gerado e perpetuado ao longo dos anos na produção sociomaterial, é necessária a participação do indivíduo em uma prática.

Portanto, a perspectiva utilizada para o estudo da aprendizagem se trata da socioprática, a qual percebe a aprendizagem como um processo resultante das realizações e interações coletivas, em oposição às abordagens puramente cognitivas. Desse modo, a aprendizagem é inseparável da experiência, dos significados e dos conhecimentos que permitem que o indivíduo participe do contexto social em que atua (GHERARDI, 2000) e sociomaterial, na medida em que se analisa a influência do sistema de linguagem e de outros elementos não humanos na construção da prática (GHERARDI; NICOLINI, 2001). É importante mencionar, na óptica da sociomaterialidade, que o conhecimento se torna material na medida em que o indivíduo atribui sentido aos objetos, aos artefatos, ou age de acordo com leis, regras compartilhadas em um dado contexto social. Essa é a natureza do conhecimento tratado neste estudo (GHERARDI, 2009; STRATI, 2012; SOARES; BISPO, 2017).

Desse modo, observamos que, ao seguir com esse quadro teórico, este estudo tem o potencial de gerar um corpo de conhecimento útil para o avanço do campo, por meio de uma perspectiva mais completa, já que utilizamos a lente das práticas, sobretudo a materialidade, e reconhecemos o papel da aprendizagem. Os estudos baseados em prática possibilitam que seja moldado um novo pensamento teórico a respeito de como o turismo é produzido, quais seus elementos caracterizadores e como ocorrem os processos de aprendizagem e geração de conhecimentos (NICOLINI; GHERARDI; YANOW, 2003) que sustentam as formas de organização dos seus elementos materiais e imateriais (CZARNIAWSKA, 2008, 2013; LEONARDI, 2012). Desse modo, falar de turismo, nessa perspectiva, é falar dos processos de aprendizagem e desenvolvimento de conhecimento de práticas sociomateriais. Tal abordagem já foi contemplada em trabalhos na área de turismo (BISPO; GODOY, 2012; CAVALCANTE; BISPO; SOARES, 2015), gastronomia (SOARES; BISPO, 2017; ALMEIDA, 2017) e na hotelaria (BARROS-SILVA, 2017).

\section{PROCEDIMENTOS METODOLÓGICOS}

Este estudo é de natureza qualitativa e a etnometodologia foi a estratégia de investigação utilizada para a pesquisa em virtude de que esse método compartilha dos pressupostos filosóficos aqui adotados (BISPO; 
GODOY, 2014). Além disso, trata-se de um modo de investigação do cotidiano em que o pesquisador observa os fatos como acontecem na prática e como os membros produzem os acontecimentos realizados (TEN HAVE, 2004; RAWLS, 2008). A etnometodologia permite compreender a prática por meio dos seus conceitos-chave (COULON, 2005): 1) realização, 2) indicialidade, 3) reflexividade, 4) relatabilidade e 5) a noção de membro, detalhados no Quadro 1.

\section{Quadro 1- Os cinco conceitos-chave da etnometodologia}

\begin{tabular}{|l|l|}
\hline \multicolumn{1}{|c|}{ Conceito } & \multicolumn{1}{c|}{ Conteúdo } \\
\hline Prática/Realização & $\begin{array}{l}\text { Indica a experiência e a realização da prática dos membros de um grupo em } \\
\text { seu contexto cotidiano, ou seja, é preciso compartilhar desse cotidiano e do } \\
\text { contexto para que seja possível a compreensão das práticas do grupo. }\end{array}$ \\
\hline Indicialidade & $\begin{array}{l}\text { Refere-se a todas as circunstâncias que uma palavra carrega em uma situação. } \\
\text { Tal termo é adotado da linguística e denota que ao mesmo tempo em que } \\
\text { uma palavra tem um significado, de algum modo "genérico", essa mesma } \\
\text { palavra possui significação distinta em situações particulares, assim, a sua } \\
\text { compreensão precisa, em alguns casos, que as pessoas busquem informações } \\
\text { adicionais que vão além do simples entendimento genérico da palavra. }\end{array}$ \\
\hline Reflexividade & $\begin{array}{l}\text { Está relacionada aos "efeitos” das práticas de um grupo, trata-se de um } \\
\text { processo em que ocorre uma ação e, ao mesmo tempo, produz uma reação sobre } \\
\text { os seus criadores. }\end{array}$ \\
\hline Relatabilidade & $\begin{array}{l}\text { É como o grupo estudado descreve as atividades práticas a partir das referências } \\
\text { de sentido e significado que o próprio grupo possui, pode ser considerada como } \\
\text { uma “justificativa" do grupo para determinada atividade e conduta. }\end{array}$ \\
\hline Noção de membro & $\begin{array}{l}\text { O membro é aquele que compartilha da linguagem de um grupo, induz a uma } \\
\text { condição de "ser” do e no grupo e não apenas de "estar". }\end{array}$ \\
\hline
\end{tabular}

Fonte: Bispo e Godoy (2014, p. 116).

Para a realização desta pesquisa, houve a imersão dos pesquisadores na Orla Marítima de João Pessoa/ PB, entre os meses de fevereiro e setembro de 2014, especificamente nas praias de Manaíra, Tambaú e Cabo Branco, onde ocorreram as observações diretas com foco na apreensão dos processos de aprendizagem dos atores sociais. Adicionalmente, foram recorridas a conversas informais sempre que surgia a necessidade de conhecer a relação de sentido que um dado indivíduo atribuía ao contexto observado, ou quando se percebia a necessidade de alguma informação/explicação sobre como esses indivíduos tinham se tornado capazes de participar de determinada atividade realizada na orla. Ao todo, 62 pessoas foram abordadas e contribuíram com esta pesquisa. Os dados das observações e das conversas informais foram registrados imediatamente em um caderno, o que possibilitou um material de análise e consulta.

Os dados foram analisados à luz dos cinco conceitos-chave da etnometodologia garfinkiliana, especificamente com base na proposta de Bispo e Godoy (2014) de, por meio de questionamentos, pautarnos na identificação das atividades que formam uma prática e os elementos que indicam realização, indicialidade, reflexividade, relatabilidade, a noção de membros, assim como pode ser observado no Quadro 2. 
Quadro 2 - Análise e interpretação de dados etnometodológicos

\begin{tabular}{|c|c|}
\hline Conceito & Pergunta de orientação analítica e interpretativa \\
\hline Prática/Realização & $\begin{array}{l}\text { As atividades identificadas representam o cotidiano da organização/grupo } \\
\text { investigado e são reconhecidas pelos seus membros como próprias e } \\
\text { características da organização/grupo ao qual pertencem? }\end{array}$ \\
\hline Indicialidade & $\begin{array}{l}\text { O conjunto de atividades identificadas apresenta uma linguagem própria da } \\
\text { organização/grupo investigados em que todos os membros compartilham dela e } \\
\text { do(s) sentido(s) que ela representa na vida cotidiana dessa organização/grupo? } \\
\text { É possível identificar jargões e/ou palavras próprias? }\end{array}$ \\
\hline Reflexividade & $\begin{array}{l}0 \text { conjunto de atividades identificadas cria ao longo do tempo na organização/ } \\
\text { grupo condições de perpetuação, modificação, ou, até mesmo, geram novas } \\
\text { atividades que são reconhecidas pelos membros como resultado do seu } \\
\text { cotidiano? }\end{array}$ \\
\hline Relatabilidade & $\begin{array}{l}\text { É possível identificar nas falas e ações dos membros da organização/grupo } \\
\text { justificativa comum para orientar a razão pela qual o conjunto de atividades é } \\
\text { realizado daquela forma e não de outra? }\end{array}$ \\
\hline Noção de membro & $\begin{array}{l}\text { O conjunto de atividades mapeadas permite ao pesquisador identificar } \\
\text { claramente quem são os indivíduos que são efetivamente da organização/grupo } \\
\text { e não apenas "estão" nele? A indicialidade e a relatabilidade são fundamentais } \\
\text { para tal reconhecimento. }\end{array}$ \\
\hline
\end{tabular}

Fonte: Adaptado de Bispo e Godoy (2014, p. 129).

\section{REFLEXÕES SOBRE O PROCESSO DE APRENDIZAGEM DO TAP NA ORLA}

É importante compreendemos o processo de aprendizagem coletivo e como os conhecimentos são gerados e compartilhados para que os elementos do TAP permaneçam em um processo contínuo de uso e refinamento. E também como ocorre a criação de sentido, principalmente pelos atores humanos locais por meio da aprendizagem situada (OU, 2009). Portanto, para falar da aprendizagem social, é necessário ponderar que ao considerar o TAP na Orla Marítima, passamos a considerar o turismo em seu caráter social, situacional e, ainda, a transversalidade de atividades e elementos humanos e não humanos que sustentam a prática. A transversalidade em questão envolve a relação entre visitantes e locais, a interação entre atores sociais humanos e não humanos, materiais e imateriais e também ao "como" as atividades são produzidas e organizadas tecendo o turismo ou, ainda, de um modo mais amplo, tecendo outras práticas que possam vir a convergir em uma prática ainda maior como o próprio turismo enquanto organização social (CZARNIAWSKA, 2008; LEONARDI, 2012).

Os processos que organizam o TAP se relacionam à experiência dos agentes, assim como ao processo de aprendizagem coletiva. A ação coletiva combina a experiência e os conhecimentos adquiridos no processo de aprendizagem fazendo com que o conhecimento da prática (Knowing-in-practice) se desenvolva (GHERARDI, 2006). Desse modo, apreende-se que o processo de aprendizagem do TAP se relaciona ao uso da Orla Marítima com fins econômicos, sociais e culturais amparado por uma forte influência do mercado turístico e as oportunidades que ele oferece aos atores sociais humanos: de um lado o empreendedorismo, seja ele em níveis micro ou macro; de outro a utilização do tempo livre e do consumo. A lógica por trás das falas dos atores sociais humanos envolve a informação de que a Orla 
Marítima é um espaço onde se concentram pessoas - estas que ali estão por uma finalidade específica, atrativos naturais e artificiais, traços culturais, entre outros.

O turismo foi revelado como um aspecto importante por meio do qual há organização social no espaço Orla Marítima e há a produção de sentido pelos utilizadores desse espaço. Mesmo sendo uma prática tão abstrata, composta por inúmeras vertentes, na fala de alguns atores sociais humanos foi perceptível o quanto essa prática representou (inicialmente) e representa uma força motriz para o uso do referido espaço. Todos os atores humanos que contribuíram com este estudo afirmaram que sua colocação na Orla Marítima ocorreu mediante uma oportunidade oferecida pelo turismo (em maior ou menor grau). Isso aponta indícios de que a prática se consolida na medida em que influencia na agência de seus atores sociais.

É assim ilustrado o que é colocado por Lave e Wenger (1991) ao afirmarem que a produção de sentido ocorre na medida em que acontece a interação "face a face" ou "coparticipação" dos atores humanos e sua relação com o corpo material e imaterial situado (GHERARDI, 2001). Nesse caso, o turismo baliza a ação e a produção de sentido na medida em que são mobilizadas ferramentas, métodos particulares, conhecimentos implícitos ou explícitos e o compartilhamento de uma linguagem comum (WENGER, 1998).

Quando se menciona a linguagem, $\mathrm{Ou}$ (2009) expõe que a indicialidade pode representar uma marca do processo de aprendizagem situada, como no caso dos atores humanos locais de João Pessoa/PB que utilizam o termo "môfi" tanto no tratamento carinhoso com os filhos quanto para denominar um grupo de marginais que agem em bando. Essa linguagem é própria desses atores, isso pode representar uma barreira para o entendimento dos não membros daquele contexto, uma vez que a mesma palavra pode oferecer sentidos distintos e antagônicos fora do contexto cultural em questão. Outros exemplos podem ser utilizados para ilustrar o resultado da aprendizagem situada, sejam eles os gestos de comunicação utilizados pelos garçons nos bares e quiosques, ou os assobios como um sinal para chamar a atenção para que um passeio ao mar engate sua partida. Esse aspecto é colocado por Gherardi e Landri (2014) como mecanismos de subscrição que permitem de forma sociomaterial a estabilização do indivíduo na medida em que produzem múltiplos significados, a exemplo, uma prestação de contas. Nesse momento, o indivíduo assume uma imagem ou status social, seja esta a de turista, agente turístico, garçom, agente de limpeza urbana, policial, artesão, entre outras.

É possível apreender, ainda, que o conhecimento situado é encharcado pelos traços históricos, sociais e materiais de uma dada comunidade e também é base para a cultura que sustenta a forma como cada indivíduo percebe o mundo ao seu redor, sua visão de mundo (GHERARDI, 2006; OU, 2009). Como exemplos, do ponto de vista econômico dos agentes dessa prática, os indivíduos utilizam do conhecimento prévio sobre a Orla Marítima para empreender, seja em um comércio formal ou informal. O espaço é estruturado por quiosques, bares e restaurantes que abrigam o comércio informal, somado à exposição de artesanatos na "passarela" da "calçadinha" (barreira construída para a proteção da calçada contra a areia lançada pelo vento, que é utilizada com assento), o aluguel de equipamentos e serviços, como os passeios de barcos e a ida à ilha de Picãozinho, no trecho da praia de Tambaú, entre outros. Para ratificar a utilização do conhecimento prático de alguns atores humanos, segue o trecho do que expressou uma agente social que, movida pelo turismo, largou sua ocupação oficial na área da saúde para se dedicar ao trabalho como artesã:

Nós somos de São Paulo [referindo-se ao marido] e estamos aqui na Paraíba há quatro anos. Nós vimos pra cá porque ele passou num concurso, ele é funcionário público e eu vim acompanhando. Lá em São Paulo eu trabalhava 
como enfermeira, mas quando cheguei aqui não gostei do piso salarial na área da saúde, então resolvi resgatar uma paixão de infância, o trabalho com fantoches. [Quando perguntado por que expor seu trabalho na Orla] Estou na Orla porque tá caro abrir minha loja, os preços de aluguel de ponto estão bem altos, então estou aqui por causa do turismo que existe aqui. Aqui tem muito movimento de pessoas, para você ter uma ideia já chegamos a lucrar R\$ 500 numa noite por causa do turismo, hoje em dia o movimento tá mais fraco, os lucros caíram bastante. [Quando perguntado o que ela tem feito para reverter a situação da queda das vendas] Percebi que muitas pessoas ficavam interessadas nos fantoches, mas não tinham o dinheiro para comprar na hora, então resolvi criar esses panfletos para trabalhar com encomendas. Criei também um perfil no Facebook e no Instagram para divulgar meu trabalho, e todas estas informações estão também no panfleto. Assim, posso enviar as encomendas por correio para pessoas de outros estados que queiram comprar os produtos (Artesã que atua na orla marítima de Tambaú - NOTAS DE CAMPO, 2014).

No trecho seguinte, o ator humano justifica o motivo que o levou a investir seus recursos em um negócio no espaço Orla Marítima. Seu relato indica um processo de conhecimento em prática que fundamenta o processo decisório de investimento e expansão dos seus serviços:

\begin{abstract}
Eu observava que muitas pessoas vinham patinar aqui na Orla e traziam seus patins, às vezes trazendo um peso a mais não é confortável pras pessoas. Então pensei em oferecer o serviço de aluguel de patins porque as pessoas alugam. Elas [as pessoas] gostam. Pra você ter uma ideia, quando cheguei aqui só tinha eu e um menino que alugava, hoje em dia eu tive que comprar mais cinco pares pra dar conta da procura e já existem outras pessoas que também alugam patins [Rapaz que aluga patins na orla marítima de Cabo Branco - NOTAS DE CAMPO, 2014].
\end{abstract}

Do ponto de vista social, as pessoas vão à Orla Marítima por saberem que irão encontrar um leque de atrativos, produtos, serviços, segurança e outras pessoas que proporcionam a elas a sensação de bemestar, alegria, possibilitada pela prática em questão. A reflexividade submerge como um modo de ilustrar a influência que existe no interesse na Orla Marítima e sua relação com a ação dos indivíduos, fazendo com que estes se organizem em torno da prática. Ressalta-se que, na perspectiva das práticas, aprender eorganizar são partes imbricadas de um processo de construção coletiva (GHERARDI, 2006; CZARNIAWSKA, 2008; BISPO, 2016b), a aprendizagem é considerada um elemento fortemente determinante na existência e desenvolvimento das organizações sociais. Como exemplo do que é apresentado, no Largo da Gameleira (Orla de Tambaú) há um espaço destinado aos pescadores, que o tipifica de certo modo reforçando um traço cultural e que caracteriza o espaço como turístico. Pessoas vão a esse lugar, tiram fotos, interagem com os pescadores, alguns levam suas varas de pescaria, outros pescam de uma maneira mais rústica. É comum observar indivíduos pescando em intervalos específicos nos horários da manhã, tarde e noite, enquanto no mar é possível ver uma quantidade considerável de pequenas embarcações ali atracadas (NOTAS DE CAMPO, 2014).

Conhecer sobre como colocar as embarcações no mar, as condições do mar, do vento, as temperaturas ideais para pescar, o tipo de isca utilizada e os pontos no mar onde pescar são tipos de conhecimentos citados pelos pescadores como algo inerente à atuação destes; o conhecimento construído de modo situado, sem a necessidade de uma formação formalizada, mas que pode ser ensinado aos novos membros que possuam o desejo de participar da comunidade de pescadores. Somado a esse conhecimento existe aquele que também é inerente à atuação dos pescadores e que é realizado de uma maneira não reflexiva, ou seja, as ações que estes desempenham sem ter a consciência de que estão desempenhando, ou aquele conhecimento que é considerado o elemento-chave no desempenho de um pescador e, portanto, não deve ser perpassado aos demais, a menos que o expert deseje que o mesmo seja transmitido.

Buscamos exemplificar a dinâmica de disseminação do conhecimento entre os membros dessa comunidade específica. Para que os conhecimentos e as habilidades sejam aprendidos pelos pescadores que ingressam em uma comunidade a fim de se legitimarem como membros, ou aqueles que já foram 
legitimados e que desejam um aprimoramento do conhecimento, é necessário que eles estejam inseridos ativamente em uma comunidade, realizando suas práticas sociomateriais (LAVE; WENGER; 1991) conforme pode ser observado no relato que segue:

\footnotetext{
Eu aprendi a pescar vendo meu pai, eu sempre vinha com ele, fazia o que ele fazia. [...] Muito tempo pescando eu aprendi muita coisa por aqui mesmo. Ele [se referindo ao pai] me ensinou muitos dos truques que sei, a forma de lançar as iscas, o sentido do peixe quando agarra na isca. Essas coisas... (Pescador - NOTAS DE CAMPO).
}

Ao se mencionar "essas coisas", o ator humano enseja aludir ao fato de que existe uma infinidade de ações que não podem ser descritas de forma simples, dando a ideia de que vigora entre eles um corpo de conhecimento situado, ou seja, a base da ação dos pescadores é pautada por um conhecimento essencialmente tácito; o conhecimento adquirido pelos pescadores perpassa gerações, fazendo com que as atividades existam e se aprimorem; a aprendizagem ocorre de forma coletiva e cotidiana. Existem tradições e hábitos entre os pescadores como, por exemplo, a forma de deslizar as embarcações sobre um rolo largo até que ela esteja no mar, o tipo de equipamento de pesca, a pescaria vespertina e noturna; e ainda, existem relações de poder as quais emergem das interações sociais, nesse caso, os experts são detentores do poder em questão (LAVE; WENGER, 1991; GHERARDI; NICOLINI; ODELLA, 1998, p.281; GHERARDI, 2006).

Com efeito, a noção de conhecimento situado também aponta as formas como os recém-chegados (novatos) se relacionam com os veteranos (membros efetivos de um grupo). Isso fica visível quando realizada uma análise aprofundada na comunidade de pescadores, assim como em outros segmentos do turismo na Orla Marítima. Nesse caso, é evocada a atuação dos trabalhadores nos quiosques. Em um específico, o proprietário atua ainda com embarcações para passeios turísticos. Os funcionários dividem seu tempo de trabalho entre o atendimento dos clientes dos quiosques, assim como atuam com os serviços oferecidos durante os passeios turísticos. Para que esses profissionais fossem admitidos no quadro operacional, foi necessário o cumprimento de pré-requisitos mínimos relacionados ao atendimento do cliente (aprendizagem formal). Esses funcionários passaram por um período de adaptação, a partir do qual se tornaram membros efetivos, estabelecendo a partir de então um conhecimento direcionado, coletivo, específico e tácito (aprendizagem informal), imbricados nas práticas que sustentam a comunidade em que atuam (LAVE; WENGER, 1991; WENGER, 1998; GHERARDI; NICOLINI; ODELLA, 1998; GHERARDI, 2006).

\section{CONSIDERAÇÕES FINAIS}

Ao apontar os caminhos que indicam os processos de aprendizagem, imbricados nos processos organizativos presentes nos conceitos-chave da etnometodologia, promovemos uma reflexão sobre o processo de aprendizagem social do turismo como prática organizativa na Orla Marítima. Evidenciamos aspectos que revelam o percurso entre aprender e organizar-se socialmente, como o caso da artesã (CZARNIAWSKA, 2008; GHERARDI, 2006). A indicialidade presente nos discursos dos atores sociais reforça o resultado da aprendizagem estabelecida pelas relações ali existentes. Outro conceito que aponta mais enfaticamente a aprendizagem coletiva se trata da reflexividade. Os indivíduos empreendem na Orla, ou passam a se vestir de determinada maneira, ou passam a executar determinadas atividades porque existe a percepção de que o espaço é propício a tais realizações e o modo como agem cotidianamente, 
ou seja, a justificativa principal para suas ações é alicerçada pela prática social - o turismo. O fato é que ao apontar o TAP, não afirmamos que ela é a única a reger/nortear o comportamento dos indivíduos no referido espaço, mas que um conjunto de outras práticas também entram em intersecção com o turismo como, por exemplo, o voluntariado apontado como uma importante prática na praia de Cabo Branco (BISPO; SANTOS, 2014) e até mesmo o esporte. Essas práticas caracterizam o espaço Orla Marítima como uma organização fruto de inúmeros processos resultantes do organizar (CZARNIAWSKA, 2013), ou simplesmente como uma textura de práticas (GHERARDI, 2006, 2009).

Acreditamos que pela Orla Marítima representar um campo de práticas, há inúmeros caminhos para a realização de estudos. Portanto, fazemos algumas sugestões nesse sentido. A primeira delas se trata de um aspecto que não pôde ser apreendido neste estudo, mesmo fazendo parte tão tênue da perspectiva de aprendizagem adotada, sendo esta a estética organizacional (STRATI, 2007; 2012; GHERARDI, 2009; SOARES; BISPO, 2017). Novos estudos podem ser empreendidos para compreender conceitos como, por exemplo, o taste, elemento por trás da realização da prática pelos indivíduos e o taste making, refinamento da prática em um processo reflexivo (GHERARDI, 2009), ou até mesmo o conhecimento estético (STRATI, 2007), aquele aplicado na utilização do sentido.

\section{REFERÊNCIAS}

ALMEIDA, L. L. Quem tem boca vai comer na rua! Inovação social na comida de rua sobre rodas como prática em João Pessoa - PB. Dissertação de mestrado, Universidade Federal da Paraíba, Paraíba, PB, Brasil, 2017.

BARROS-SILVA, L. Sustentabilidade como prática sociomaterial no processo de gerenciamento de um hotel em João Pessoa - PB. Dissertação de mestrado, Universidade Federal da Paraíba, Paraíba, PB, Brasil, 2017.

BISPO, M. S. Tourism as practice. Annals of Tourism Research, v. 61, p. 170-179, 2016 a.

O Turismo como Prática Cultural Organizativa, Sociomaterial e Estética. RIGS - Revista Interdisciplinar de Gestão Social, v. 5, p. 125-137, 2016b.

BISPO, M. S.; GODOY, A. S. Etnometodologia: uma proposta para pesquisa em estudos organizacionais. Revista de Administração da Unimep, v. 12, n. 2, Maio/Agosto, 2014.

A Etnometodologia enquanto Caminho Teórico-metodológico para Investigação da Aprendizagem nas Organizações. RAC - Revista de Administração Contemporânea, v. 16, p. 684-704, 2012.

BISPO, M. S.; MELLO, A. S. A miopia da aprendizagem coletiva nas organizações: existe uma lente para ela? Revista Gestão e Planejamento, Salvador, v. 12, n. 3, p. 728-745, Set./Dez, 2012.

BISPO, M. S. A aprendizagem organizacional baseada no conceito de prática: contribuições de Silvia Gherardi. RAM - REV. ADM. MACKENZIE, v. 14, n. 6, Edição Especial. São Paulo, SP. Nov./Dez., p. 132161, 2013.

BISPO M. S.; SANTOS, I. S. A. A organização do cotidiano na orla de João Pessoa: um olhar etnometodológico da prática do voluntariado. Farol - Revista de Estudos Organizacionais e Sociedade, Belo Horizonte, n. 2, p. 379-416, dez. 2014. 
BRASIL. Ministério do Turismo. Economia do turismo cresce no Brasil. Disponível em: 〈http://www. turismo.gov.br/turismo/noticias/todas_noticias/20140417-1.html〉. Acesso em: 04 jul. 2014.

CAVALCANTE, E. D. C.; BISPO, M. S.; SOARES, L. C. Praia, Sol e Mar: um mergulho na compreensão da orla marítima de João Pessoa (PB) como organização. Gestão \& Regionalidade, v. 31, n. 92, p. 103-119, 2015.

COHEN, E.; COHEN, S. A. "Current Sociological Theories and Issues in Tourism". Annals of Tourism Research, v. 39, n. 4, p. 2177-2202, 2012.

COULON, A. La Etnometodologia. 3 ed. Madrid: Cátedra, 2005.

COUSINS, J.; O’GORMAN, K.; STIERAND, M. Molecular gastronomy: cuisine innovation or modern day alchemy? International Journal of Contemporary Hospitality Management, v. 22, n. 3, p. 399-415, 2010.

CZARNIAWSKA, B. Organizations as obstacles to organizing. In: ROBICHAUD, D.; COOREN, F. (Ed.). Organizations and organizing. Materiality, agency, and discourse. New York: Routledge, p. 3-22, 2013.

CZARNIAWSKA, B. Organizing: how to study it and how to write about it. Qualitative Research in Organizations and Management. An International Journal, v. 3, n. 1, p. 4-20, 2008.

DIDIER, J. M. O. L.; LUCENA, E. A. Aprendizagem de Praticantes da Estratégia: contribuições da aprendizagem situada e da aprendizagem pela experiência. Organizações \& Sociedade - 0\&S, v. 15, n. 44. Janeiro/Março, p. 129-148, 2008.

DUIM, R. V. Tourismscapes: an actor-network perspective. Annals of Tourism Research, v. 34, n. 4, p. 961-976, 2007.

DUIM, R. V.; REN, C.; JÓHANNESSON, G. Actor-Network Theory and Tourism: ordering, materiality and multiplicity. Routledge, 182p., 2012.

EDENSOR, T. Performing tourism, staging tourism. Tourist Studies, v. 1, n. 1, 2001, p. 59-81.

ENZENSBERGER, H. M. A Theory of Tourism. New German Critique, n. 68, Special Issue on Literature. Spring - Summer, p.117-135, 1996.

FOX, S. From management education and development to the study of management learning. In: BURGOYNE, J.; REYNOLDS, M. Management learning: integrating perspectives in theory and practice. London: Sage Publications, 1997.

FREIRE, P. Pedagogia do oprimido. Rio de Janeiro, RJ: Paz e Terra, 1970.

GARFINKEL, H. Studies in Ethnomethodology. Prentice-Hall, Englewood Cliffs, NJ, 1967.

GHERARDI, S. How to conduct a practice-based study: problems and methods. Cheltenham: Edward Elgar, 2012.

Practice? It's a matter of taste! Management Learning, v. 40, n. 5, p. 535-550, 2009. 2006.

. Organizational knowledge: the texture of workplace learning. Oxford: Blackwell Publishing,

From organizational learning to practice-based knowing. Human Relations, v. 54, n. 1, p. 131139, 2001. 
. Practice-Based Theorizing on Learning and Knowing in Organizations. Organization, v. 7, n. 2, p. 211-223, 2000.

GHERARDI, S.; LANDRI, P. "I Sign, Therefore I am" (Un)stable Traces of Professional Practices. Profission \& Profissionalism, v. 4, n. 2, 2014.

GHERARDI, S.; NICOLINI, D. The Sociological Foundations of Organizational Learning. In: DIERKES et al., Handbook of organizational learning and knowledge. Oxford: Oxford University Press, cap. 2, p. 35-60, 2001.

GHERARDI, S.; NICOLINI, D.; ODELLA, F. Toward a social understanding of how people learn in organizations: the notion of situated curriculum. Management Learning, v. 29, n. 3, p. 273-297, 1998.

HAMMERICH, K. Sociology of Leisure. Kolner Zeitschrift Fur Soziologie Und Sozialpsychologie, v. 55, n. 4, p. 815-816, 2003.

JARVIS, P. Towards a Comprehensive Theory of Human Learning: lifelong learning and the learning society. New York: Routledge, 2006.

JOÃO PESSOA. A capital: João Pessoa é surpreendente. Disponível em: 〈http://www.joaopessoa. pb.gov.br/secretarias/setur/joaopessoa/>. Acesso em: 27 mai. 2014.

JÓHANNESSON, G. T. "Tourism translations: actor-network theory and tourism research". Tourist Studies, v. 5, n. 2, p. 133-150, 2005.

LAMERS, M.; DUIM, R.; SPAARGAREN, G. The relevance of practice theories for tourism research. Annals of Tourism Research, v. 62, January, p. 54-63, 2017. Disponivel em: 〈https://doi.org/10.1016/j. annals.2016.12.002>.

LATOUR, B. Reassembling the social. Oxford: Oxford University Press, 2005.

LAVE, J.; WENGER, E. Situated Learning: legitimate peripheral participation. Nova York: Cambridge University Press, p. 27-43, 1991.

LEONARDI, P. M. Materiality, Sociomateriality, and Socio-Technical Systems: What Do These Terms Mean? How Are They Related? Do We Need Them? In: LEONARDI, P. M.; NARDI, B. A.; KALLINIKOS, J. (Ed.). Materiality and Organizing: social interaction in a technological world (p. 25-48). Oxford: Oxford University Press, 2012.

MALCOM, D.; MANSFIELD, L. The quest for exciting knowledge: developments in figurational sociological research on sport and leisure. Politica y Sociedad, v. 50, n. 2, 2013, p. 397-419, 2013.

MARSHALL, N. Cognitive and Practice-based Theories of Organizational Knowledge and Learning: Incompatible or Complementary? Management Learning, v. 39, n. 4, p. 413-435, 2008.

NECHER, M. C. "Implicações epistemológicas en la investigación turística". Estudios y Perspectivas en Turismo, v. 20, n. 2, p. 384-403, 2011.

NICOLINI, D. Practice Theory, Work, \& Organization: an introduction. Oxford: Oxford University Press, 2013.

NICOLINI, D.; GHERARDI, S.; YANOW, D., (Ed.). Knowing in Organizations: a pratice-Based Approach. Armonk, NY: M. E. Sharpe, 2003.

ORLIKOWSKI, W. J.; SCOTT, S. V. Sociomateriality: Challenging the Separation of Technology, Work and Organization. The Academy of Management Annals, v. 2, n. 1, p. 433-474, 2013. 
OU, H. Situated knowledge: a practice-based view on intercultural interaction. Acad Manage Proc. August 1:1 1-6, 2009.

PAGET, E.; DIMANCHE, F.; MOUNET. A. Tourism Innovation Case An Actor-Network Approach. Annals of Tourism Research, v. 37, n. 3, p. 828-847, 2010.

RAWLS, A. W. Harold Garfinkel, ethnomethodology and workplace studies. Organization Studies, v. 29, n. 05, p. 701-732, 2008.

RECKWITZ, A. Toward a theory of social practices: a development in culturalist theorizing. European Journal of Social Theory, v. 5, n. 2, p. 243-263, 2002.

REN, C. "Non-human agency, radical ontology and tourism realities". Annals of Tourism Research, v. 38, n. 3, p. 858-881, 2011.

SCHATZKI, T. R. Introduction: practice theory. In: SCHATZKI, T. R.; KNORR CETINA, K.; VON SAVIGNY, E., (Ed.). The Practice Turn in Contemporary Theory, p. 01-14. New York: Routledge, 2001.

SOARES, L. C., BISPO, M. S. A Aprendizagem do Cozinhar à Luz das Práticas Sociais e da Estética Organizacional. Brazilian Business Review, v. 14, n. 2, p. 247-271, 2017.

SRATI, A. Knowing in Practice: aesthetic understanding and tacit knowledge. In: GHERARDI, S.; STRATI, A. Learning and knowing in practice-based studies. Edward Elgar Pub, Cheltenham, UK, 2012.

STRATI, A. Organização e estética. Rio de Janeiro: FGV, 2007. 332p.

TEN HAVE, P. Understanding qualitative research and ethnomethodology. London: Sage, 2004.

WENGER, E. Communities of Practice: learning, meaning and identity. New York: Cambridge University Press, p. 3-17, 1998.

Communities of practice and social learning systems. In: NICOLINI, D.; GHERARDI, S.; YANOW,

D. Knowing in organizations: a practice based approach. New York: ME. Sharpe, 2003. p. 76-99. 